Archivum, LXIX, 2019, pp. 123-160

\title{
Lope de Estúñiga y la autoría de las Coplas de la panadera
}

\author{
Jesús Fernando Cáseda Teresa \\ IES VAlLe del Cidacos \\ CALAhorra \\ casedateresa@yahoo.es
}

Recibido: 26/05/2018

Aceptado: 10/05/2019

\section{RESUMEN:}

En este estudio, analizo la autoría de las Coplas de la panadera. Procedo a rebatir la autoría de Juan de Mena, de Rodrigo Cota, de los Manrique, de Pedro de Escavias y de Antón de Montoro. Concluyo que el autor es un miembro de la familia Estúñiga, Lope de Estúñiga, hijo del mariscal de Navarra y Castilla, Íñigo Ortiz de Estúñiga. Para ello, y tras seguir la pista que ofrece Juan de Mena, comparo una obra muy parecida a las Coplas de la panadera, el Decir de Lope de Estúñiga sobre la cerca de Atienza (1446), con la que coincide formalmente en la estructura métrica, rima, estribillo, formas léxicas, así como en la común crítica contra las guerras civiles entre los reinos peninsulares. Analizo las razones textuales que explican la autoría: el autor se esconde detrás de su familia y señalo la aparición de personas vinculadas con la vida de Lope de Estúñiga (los familiares de su primo Suero de Quiñones, con quien participó en el famoso paso honroso; el conde de Huelma - localidad que él ayudó a liberar, en su única acción bélica conocida-; el primo de su padre, marqués de Santillana...). Finalmente, intento explicar la causa de la escritura de la obra, en su doble condición de navarro y de castellano: como nieto del rey Carlos III el Noble y del justicia mayor 
de Castilla - Diego de Estúñiga- se burla por igual de unos y otros por su obstinación en una guerra fratricida.

PALABRAS CLAVE: Siglo XV, Coplas de la panadera, autoría, Lope de Estúñiga, Juan de Mena.

Lope de Estúniga and the authorship of the Coplas de la panadera

\begin{abstract}
:
In this study, I analyze the authorship of the Coplas de la panadera. I proceed to refute the authorship of Juan de Mena, Rodrigo Cota, the Manrique, Pedro de Escavias and Antón de Montoro. I conclude that the author is a member of the Estúñiga family, Lope de Estúñiga, son of the mariscal of Navarre and Castile, Íñigo Ortiz de Estúñiga. To do this, and after following the track offered by Juan de Mena, I compare a work very similar to the Coplas de la panadera and the Decir de Lope de Estúñiga sobre la cerca de Atienza (1446), with the one that formally coincides in the metric structure, rhyme, lexical forms, as well as the common criticism against the civil wars between the peninsular kingdoms. I analyze the textual reasons that explain the authorship: the author hides behind his family and I point out the appearance of people linked to the life of Lope de Estúniga (the sons of his cousin Suero de Quiñones, with whom he participated in the famous paso honroso; the Count of Huelma - locality that he helped to liberate, in the only known warlike action; the cousin of his father, Marquis of Santillana, ...) Finally, I try to explain the cause for the writing of the work: in his double condition of Navarrese and Castilian, as grandson of King Carlos III el Noble and of the greater justice of Castile - Diego de Estúñiga - he mocks both equally for their obstinacy in a fratricidal war.
\end{abstract}

KEY WORDS: XV century, Coplas de la panadera, authorship, Lope de Estúñiga, Juan de Mena.

\title{
1. La autoría de las Coplas de la panadera según la crítica No son muchos los trabajos filológicos o históricos que se han pronunciado acerca de la autoría de la obra y, en bastantes oca- siones, se han conformado con repetir el conocido trío de candi- datos propuestos a lo largo de los siglos: Juan de Mena, Rodrigo Cota o Íñigo Ortiz de Estúñiga o de Zúñiga.
}


Desde Italia, Alberto Vàrvaro $(1964,110)$ y Paola Elia $(2002$, 45) han prestado atención al cruce de poemas entre este último, Íñigo Ortiz de Estúñiga, y Juan de Mena, tras acusar Mena a aquel de ser el autor del poema. Alberto Vàrvaro pensó que fue el anciano miembro y padre de los Estúñiga, presente en la batalla de Olmedo de 1445, quien pudo escribir la obra, cuya idea sobre su paternidad desarrollo más adelante en el apartado correspondiente. Por su parte, Miguel Ángel Pérez Priego ni apoya la tesis de que el autor de la obra es el poeta Juan de Mena, ni tampoco la desestima. De hecho, en sus Estudios sobre la poesía del siglo $X V$ señala que ya Juan de Lucena se refirió a muchas composiciones de "vituperio y motejo" $(2013,134)$ del escritor cordobés hoy perdidas. A este respecto, Menéndez Pelayo (1890, L) nunca pensó que Mena, poeta de excelentes calidades literarias, fuera el autor de las Coplas de la panadera.

Marcos Álvarez ha dado fundadas razones para desechar esta última posibilidad - que Mena fuera el autor-. Por ello, y tras analizar diversas versiones de las composiciones que se cruzan Mena e Íñigo Ortiz de Estúñiga, concluye que se trata de textos que formaron parte de una versión inicial más larga de la obra, desconocida en la actualidad, y que fueron desgajados de los propios manuscritos en una muestra de ira e irritación por parte de los aludidos o sus próximos, refiriéndose Marcos Álvarez a una manifiesta "mutilación". Por ello, establece como conclusión que

[...] la discordancia que muestran los manuscritos sobre quién sea el autor de los versos, se puede concluir sin aventurar demasiado que no fue Mena quien los escribió $(1979,453)$.

Julio Rodríguez Puértolas, en el estudio introductorio a la edición de la obra en el volumen de Poesía crítica y satírica del siglo $X V$, considera que

Con todo, las Coplas de la Panadera deben seguir siendo consideradas como anónimas, y ello a pesar de otros detalles que, por 
caminos distintos, pudieran llevarnos, de nuevo, a Juan de Mena $(1981,128)$.

Paola Elia, autora de una excelente y tal vez definitiva edición de la obra, basada en la versión "más breve transmitida por el Pequeño Cancionero", a su parecer "la más antigua" por no haber estado presumiblemente sujeta a contaminación de copistas que ampliaran y reelaboraran el texto, lo califica de "anónimo" (2002, 45), pese a que en su trabajo de 1983 no cree improbable la atribución propuesta por Alberto Vàrvaro a Íñigo Ortiz de Estúñiga.

Miguel García-Bermejo Giner no se atreve a proponer a un autor de la obra, y en su lugar señala que

A pesar de esas múltiples conjeturas, lo que nadie parece poner en duda es que su autor fue un noble que hizo uso extenso de formas y temas cultos y populares $(2015,87)$.

Indica a este respecto García- Bermejo que

No parece imposible, por tanto, que un noble se entretuviera con un relato truhanesco, pero no excesivo, de sus compañeros de corte, hundiendo sus burlas en el capital inmaterial que desde las Partidas se le supone al noble $[\ldots](2015,96)$

Fernando Castillo Cáceres no se aventura tampoco a la hora de dar un nombre, pero señala algo que para mí tiene cierto interés:

La batalla es el acontecimiento al que se refiere, pero en ningún momento aparece ni descrita ni citada. Este hecho histórico es el referente pero no está presente en ninguna de las coplas de manera explícita $(2009,208)$.

La pregunta que podríamos hacernos sería - siguiendo la consideración transcrita de Fernando Castillo- la siguiente: ¿tal 
vez porque no estuvo presente su autor en los hechos bélicos de aquel día?

Fernando Castillo no dice nada al respecto, pero señala que se trata de una "anticrónica de la Caballería, de crónica bufa de la batalla de Olmedo" $(2009,208)$. Niega, a este respecto, que la obra tenga alguna clase de intención satírica con respecto a la nobleza como estamento - postura que había defendido previamente N. Guglielmi (1970)-, sino que se trata de una crítica de personajes individuales, que aparecen por su nombre, siempre caracterizados por su cobardía y falta de valor. Se trata, según el investigador citado, de un "repertorio de antifama" (2009, 209).

Y señala algo que me parece interesante:

Un aspecto destacable de las Coplas es su carácter de reverso de obras que se han ocupado del mismo acontecimiento como la Crónica de Álvaro de Luna, un contraste que ya fue destacado en su día por la crítica $(2009,208-209)$.

Indica también que, frente a las Generaciones y semblanzas de Fernán Pérez de Guzmán, en las Coplas de la panadera "la relación de personajes está determinada en su mayor parte por la indignidad y la reprobación" $(2009,282)$.

Bien es cierto que ambas obras citadas, Generaciones y semblanzas y la Crónica de Álvaro de Luna, parecen ser posteriores a las Coplas, por lo cual no podemos hablar ciertamente de las Coplas de la panadera como una respuesta metaliteraria.

Hecho el diagnóstico, sin embargo, y expuestas las características de la crítica en la obra, la pregunta a hacernos sería, ¿por qué su autor escribió tal obra? Y a ello es a lo que prácticamente ningún crítico responde. A este respecto, Denise K. Filios no propone a ningún autor de la obra, aunque en su análisis considera que la parodia de las Coplas entra en la categoría de la heteroglosia: 
The Coplas de la panadera's complete elimination of order shows it to be a counter-narrative of the Battle of Olmedo, appropriating the rhetoric of the official narrative in order to challenge its authoritative function. The panadera's words are dialogic, as is all parodic discourse in that it appropriates and recontextualizes others' words;parody can more specifically be termed heteroglossia, defined byMikhail Bakhtin as "another's speech in another's language, serving to express authorial intentions but in a refracted [...] (2003, 361).

Su valioso trabajo, interesante para la comprensión de la reescritura histórica de los hechos poetizados, sin embargo no se aventura en la propuesta de un autor. Y tampoco, por desgracia, explica el porqué de su elaboración. Y esta es la pregunta, a mi parecer, más relevante. Así como también una explicación de la postura que asume el autor de las Coplas de la panadera: contra tirios y troyanos; esto es, contra los partidarios de Juan de Navarra y los aragoneses, por un lado; y contra Juan II de Castilla y los castellanos por el otro. Quizás estas sean las dos preguntas que hemos de responder para poder atribuir la obra a un autor concreto de una forma convincente: ¿qué pretendió? y ¿por qué atacó a los dos bandos enfrentados? Este es el objeto del trabajo que ahora principio.

\section{Análisis de posibles candidatos a la autoría de Las coplas de la panadera}

Las Coplas de la panadera, obra heterodoxa y subversiva, ocultó desde un primer momento a su autor, al igual que los conocidos ejemplos de las Coplas del provincial o las Coplas de Mingo Revulgo por razones evidentes. Sabemos que, sin duda, fueron escritas por un noble o miembro de una familia conocida, por su familiaridad con los linajes y con las personas que se citan dentro de la obra, según expresa también Miguel García-Bermejo como ya he señalado. Contemporáneo de los hechos que poetiza - primera batalla de Olmedo, 19 de mayo de 1445-, se han barajado diver- 
sas posibilidades. Entre otros, a los ya expresados Rodrigo Cota o a Juan de Mena: los mismos que se suelen mencionar habitualmente como autores de las coplas aludidas y de La Celestina.

El caso de Rodrigo Cota resulta mucho más problemático, toda vez que no resulta creíble su relación con los nobles caballeros-castellanos, navarros y aragoneses- que se nombran en la obra ${ }^{1}$. Por el contrario, su vida, muy localizada en Toledo, le mantuvo ajeno a las cuestiones bélicas de su época en las que sabemos que ni intervino ni se reflejaron en ningún caso en las pocas obras que de él conocemos. Por tanto, su autoría debe ser desechada desde el momento en que, como intuimos, el autor ha de buscarse dentro del mundo de la nobleza y no en el de los judeoconversos.

La atribución de la obra a Juan de Mena ha tenido algunos adeptos como los ya señalados en el apartado anterior. El buen conocimiento por parte de Mena de las personalidades que aparecen retratadas, su excelente manejo dentro del mundo político, el trato habitual con el rey Juan II y con el condestable Álvaro de Luna y, en definitiva, su pertenencia a la élite y al restringido círculo de los cortesanos reales pueden sostener la hipótesis de su autoría ${ }^{2}$. Sin embargo, el carácter de su poesíasiempre exquisito-, el lenguaje, las formas cultas que suele emplear y los temas que trata habitualmente, bajo un punto de vista casi siempre adulador, dejan pocas opciones para atribuirle una obra en momentos soez como las Coplas de la panadera. Para Menéndez Pelayo, su atribución sería una agradable sorpresa,

1 Su mejor estudioso, el profesor Francisco Cantera Burgos, no alude en ninguno de sus trabajos a Cota como posible autor de la obra, ni siquiera en su estudio monográfico (2011). Para analizar el tipo de literatura satírica de la época, en la que sin duda se sitúa nuestra obra, véase el trabajo de Rodríguez Puértolas, J, sobre la poesía crítica y satírica en el siglo XV (ed.) (1981) y el de Guglielmi, N. (1970, 49-104 ) para las Coplas de la panadera.

2 Sigue siendo de obligada lectura el libro de Lida de Malkiel, Ma . R. (1950), que sin embargo no se refiere en ningún caso a una posible autoría de la obra por Juan de Mena. 
aunque en realidad no creyó en ningún momento que este fuera su creador ${ }^{3}$.

No hemos de perder de vista un detalle. En la obra se dice en varias ocasiones "vi"4: "Vi al obispo de Barrientos" (LP: v. 26); "Vi sentado en una hastera / al segundo contador" (LP, vv. 185 y 186). Quizás, por tanto, hayamos de restringir el conjunto de nobles y personajes de relevancia que pudieron escribir la obra a los que participaron en la empresa bélica. Aunque el uso del verbo "vi", muchas veces presente en las composiciones de la época, tal vez solo intente dar realismo a lo que se poetiza, mostrándose el propio autor como testigo de los hechos.

Entre los poetas que participaron en la batalla de Olmedo de 1445 tenemos a los siguientes: el marqués de Santillana en el bando de los partidarios de Juan II; a Pedro de Escavias y Rodrigo Manrique, entre el de los aragoneses y navarros. Sin embargo, debemos desechar a algunos de ellos. De Santillana, todavía no marqués - aunque ya se lo había prometido el condestable si participaba en su bando-, se dice lo siguiente:

Con habla quasi extrañera, armado como francés, el noble, nuevo marqués su valiente voto diera; e tan rezio acometiera los contrarios, sin más ruego, que bivas llamas de fuego paresçió que les pusiera. (LP: vv. 217-224)

3 Señala a este respecto que "Si son realmente de Juan de Mena - escribe- , las famosas Coplas de la Panadera, probarían que alguna vez el grave autor de las Trescientas puso la sátira más personal y picante al servicio de su justa y patriótica indignación contra los perpetuos revolvedores y enemigos de la quietud del reino" (Menéndez Pelayo; 1890, L).

4 Citaré por la edición de Elia, P. (ed.) (2002). En adelante: LP. 
No parece muy lógico que, tal y como aparece retratado en la obra Íñigo López de Mendoza, podamos atribuir al mismo la obra. Cierto es que no resulta maltratado en los últimos versos, e incluso se habla bien de él. Pero los dos primeros - e incluso la acusación de "noble, nuevo marqués" alusiva a su actitud interesada al acudir a la batalla, a lo que era en principio remiso- no nos permiten atribuirle su paternidad.

Menos todavía a Gómez Manrique o a Jorge Manrique partidaria la familia del bando de los infantes de Aragón-, habida cuenta de la forma tan despectiva en que se dirige el autor de las Coplas a Rodrigo, hermano del primero y padre del segundo:

Con lengua brava, parlera,

y el coraçón de alfeñique,

el comendador Manrique

escogió bestia ligera,

y dio tan gran correndera

fuyendo muy a desora,

que seys leguas en un hora

dexó tras sí la barrera. (LP: vv. 57-64)

En la obra son solo un poco mejor tratados los nobles del bando navarro y aragonés, quizás por ser el perdedor; aunque el autor se muestra, en ocasiones, bastante duro con ellos, entre otros con Rodrigo Manrique. Sin embargo, el anónimo autor se refiere al rey de Navarra como "buen rey de Nabarra" en estos términos, expresando su valor:

El de Olmedo cabeçera, que era el buen rey de Nabarra, no se fue meter tras barra, antes bien se combatiera; y a un caballero asiera al qual dio assaz cuchilladas, 
que lo hizo mil tajadas

junto con una ribera. (LP: vv.297-304)

Y aunque al infante de Aragón lo considera atribulado en sus maniobras guerreras, no lo trata de cobarde, como en los otros casos. El retrato de su actitud es, sin embargo, también negativo, acusándolo de ser el causante de la derrota de los suyos.

Con discreçión muy somera,

más que con seso constante,

el ardid señor infante,

fuera a dar de cabeçera

en la batalla primera

que delante sí falló;

por lo qual no dudo yo

que su gente se perdiera. (LP: vv. 305-312)

Entre los poetas del bando navarro-aragonés, el que más y mejor poetizó el tema de la primera batalla de Olmedo fue Pedro de Escavias, luego alcaide de Andújar, en la actual provincia de Jaén, en dos composiciones ${ }^{5}$. En una de ellas (Romance que fizo al señor Infante don Enrique, Maestre de Santiago), apenas habla de la batalla, solo al final:
Miércoles era por mayo
ya después del medio día
quando asomó el rey don Juan
con su gente bien rregida
con tronpetas y atabales
dando muy gran bosería
su pendón real tendido
llamando todos Castilla 
mas como'l can que con rrauia

de su señor tyra y tyra

salimos a recebillo

a los canpos do venía

ovimos la gran batalla

cerca d' Olmedo esa villa

do fuimos todos vencidos

por muy gran desdicha mía (Uhagón; 1900, 528).

La parte anterior del poema es una alabanza del infante, fallecido dos meses después de la confrontación bélica a consecuencia de las heridas sufridas, y en ella se cuentan los antecedentes políticos de la lucha. A Escavias no le interesa tanto el relato de la pelea, sino que trata de justificar la acción guerrera y la entrada en Castilla de don Enrique.

En las Coplas fechas sobre las deuisiones del Rey no por la privanza del Condestable don Alvaro de Luna con el senior Rey don Juan el segundo quando la batalla d' Olmedo de Pedro de Escavias encontramos una sátira antipanadera. En esta obra se le aparecen a su autor viejos nobles ya fallecidos y su rey, también muerto, padre de Juan II, Enrique III. Entonces - viene a decir su autor-, sí había una verdadera armonía en el reino: los nobles apoyaban a su rey y no existían las luchas encarnizadas que luego tuvieron lugar. Obsérvese el desfile literario- como en las Coplas de la panaderade la nobleza en el texto de Escavias:

Vinien compañía daquestos perrlados el arcobispo don Pedro Tenorio vinien los d' Acuña vinien los d' Osorio vinien los Mendoças vinien los Furtados vinien Sandouales no muncho alongados vinien los Guzmanes cubiertos de niebla vinie don Enrrique el Conde de Niebla y los de Velasco en vno ayuntados [...] (Uhagón; 1900, 526) 
Coincide, sin embargo, una idea - la necesidad de acabar con la división del reino- con lo que se dice en los últimos versos de las Coplas de la panadera:

Tú, Señor, que eres minera

de toda virtud divina,

sácale tu melezina

de la tu sancta triaquera;

porque ya, Señor, siquiera

aya más paz algún rato,

ca del dicho desbarato

a muchos queda dentera. (LP: vv. 345-352)

El tono de todo él es absolutamente contrario al de las Coplas, aunque coinciden ambos en la sátira de la nobleza durante el gobierno de Juan II.

Escavias pertenece al círculo de poetas de Jaén, donde localizamos también a Hernán Mexía ${ }^{6}$ y al ropero Antón de Montoro ${ }^{7}$. Se ha llegado a atribuir la autoría a este último, judeoconverso cordobés, buen amigo del marqués de Santillana, de Mena, de Rodrigo Cota y de Juan Álvarez Gato. Sin embargo, sus poemas y su biografía, sin estridencias, no permiten considerarlo su autor. Además, no es noble, sino un judeoconverso, con oficio muy digno, pero humilde: sastre y vendedor de ropa por las calles, de lo que fue acusado por otros poetas. Marcella Ciceri y Julio Rodríguez-Puértolas, en el estudio a la edición de sus poemas, califican de "descabellada atribución" la de las Coplas de la panadera al escritor cordobés $(1990,29)$.

6 Véase Morales, M (1997).

7 Véase Costa, M. (1990). También VV.AA. (1977), en el trabajo colectivo con ocasión del quinientos aniversario de su muerte. 


\section{La atribución a Íñigo Ortiz de Estúñiga}

Desde muy temprano, se relacionó la escritura de las Coplas de la panadera con el noble Íñigo Ortiz de Estúniga, ya anciano en la batalla, acompañado por su hermano Pedro de Zúñiga o Estúñiga, asistido este por sus ayudantes a causa de diversas dolencias. Mena, enterado de esta paternidad, y enfadado por entender que las Coplas eran hirientes e injustas por el tratamiento que se hacía de nobles amigos que, a su parecer, habían tenido un comportamiento heroico, o al menos no cobarde como aparece en la obra, dirigió unos duros versos contra Íñigo Ortiz de Estúñiga que dicen así ${ }^{8}$ :

Íñigo, no mariscal,

capitán de la porquera,

más liviano que cendal

ni que flor de ensordadera;

maldecides con dentera

a quien merece corona

otros ponen la persona

vos parláis de talanquera

Respondió Íñigo Ortiz de Estúñiga al ofensor con otros versos en que lo acusaba de judío:
Hanme dicho, Juan de Mena,
que en copla mal me tratastes:
pues os juro al que matastes
que no os me vais sin pena
salvo si lo desordena

8 Los tres poemas citados han sido transcritos del manuscrito con el título Algunas coplas de La Panadera, que se halla en la Real Academia de la Historia: Signatura: 25, fo 201 (2aㅡ foliación). El texto los señala así: “Diálogo entre Juan de Mena e Iñigo de Zúñiga, mariscal de Castilla". Recuperado de: http://bibliotecadigital.rah. es/dgbrah/es/consulta/registro.cmd?id=50158. [Consultado el 25/10/2018]. Reproduce las tres composiciones Rodríguez Puértolas, J. (1981), pp. 180 y 181. Y también Pérez Priego, M.A., (2013), p. 135 los correspondientes a Juan de Mena. 
por punto de barahá

aquel que libró a Joná

del vientre de la ballena9.

Y todavía Juan de Mena contestaría de esta forma:

Don cara de la aguzadera

aquesto deciros oso:

Que andáis más peligroso

que redoma sin vasera;

mas dolada calavera,

flacos hechos, ruines manos,

lanza vil, sesos livianos,

andaos bien la parlera ${ }^{10}$.

No cabe mayor prueba para negar la autoría de Mena de las Coplas de la panadera que la lectura de los anteriores versos, a no ser que lo creamos mentiroso y redomado hipócrita.

Gonzalo Argote de Molina recoge al final de su obra Nobleza de Andalucía, como fuente "de la que se ha valido" las "Coplas de la panadera del mariscal Íñigo Ortiz de Zúñiga o Estúñiga"11. Argumento que parece no cuestiona en ningún momento.

Alberto Vàrvaro, como ya he señalado, expone su punto de vista acerca de la paternidad de Íñigo Ortiz de Estúñiga, basándose en el hecho de que, en su composición de respuesta a Mena, no niega ser el autor de la obra:

[...] il maresciallo risponde, si noti, senza negare affatto di essere l'autore delle Coplas e quindi i dubbi che tanto a lungo si sono protratti sull'autore di quest'opera non hanno ragione alcuna di

9 Ibidem.

10 Ibidem.

11 Cito por la edición de 1866. 
sussistere. Lo Stuñiga si limita invence a rinfacciare a Mena un'origine giudaica, ed avrà senza dubbio ragione, come credeva M.R. Lida de Malkiel (1964, 110).

En realidad, si hacemos una lectura literal del poema de Íñigo Ortiz de Estúñiga, parece que este no ha leído la composición de Mena, pues señala lo siguiente: "Hanme dicho, Juan de Mena, / que en copla mal me tratastes". La referencia a haber sido informado de los insultos - y no a haber leído la copla - supone que solo tiene noticia de que aquel lo ha injuriado y ahora procede a defenderse acusando a Mena de judío. Creo por tanto que, cuando Íñigo de Estúñiga se defiende de Mena lo hace simplemente frente a los insultos que lanza contra él y no por la acusación de ser el autor de las Coplas de la panadera. Acusación que, creo, desconoce.

En el caso de Paula Elia, y como ya he señalado, en su estudio de la última edición de las Coplas de la panadera en El "Pequeño Cancionero" (2002) se limita a señalar lo siguiente:

Han sido atribuidas a Juan de Mena y al Mariscal de Castilla, Íñigo Ortiz de Stúñiga. Algunos manuscritos de la tradición añaden al final de las coplas una disputa poética entre estos dos autores que, posiblemente, alude a la paternidad de la composición (2002, 45)..

Desconozco si Íñigo Ortiz de Estúñiga escribió algo más que la poesía que nos ha llegado porque, al margen de los versos que se cruza con Juan de Mena y dos composiciones recogidas en el Cancionero de Baena, no sabemos que escribiera ningún otro poema. El primero de estos dos es una respuesta al "judino Juan Alfonso", escrito en forma satírica y de tono parecido al que dirige contra Juan de Mena. Comienza así: "Señor, buen frontero lengua de Samsón /ardid como liebre entre las laçadas" [... $]^{12}$.

12 Dicho Juan Alfonso es Juan Alfonso de Baena, el recolector del Cancionero que recibe su nombre. Según Sánchez, T.A., "no solo es escribiente o copiante del 
El segundo es una respuesta, igual de satírica, contra un decir de Fernán Pérez de Guzmán, señor de Batres, que comienza: "Vos debedés fazer llantos / pues vuestra fama se daña" según Amador de los Ríos (1863, 424).

Sin embargo, es muy conocido el caso de su hijo, el poeta Lope de Estúñiga, cuyas composiciones encontramos en el cancionero que recibe su nombre y en otros lugares, hasta totalizar más de una treintena de poemas. Es muy probable - y esa es la hipótesis que manejo- que el informante de Juan de Mena confundiera a Íñigo Ortiz de Estúñiga con el verdadero autor de la obra, el poeta Lope de Estúniga, tercero de sus hijos. Las razones para proponer dicha atribución son diversas y abarcan desde el plano estrictamente literario, al biográfico, como a continuación señalo, así como notables coincidencias de las Coplas de la panade$\mathrm{ra}$ con algunas composiciones suyas.

\section{Lope de Estúñiga y las Coplas de la panadera}

Lope de Estúñiga o de Zúñiga fue el tercer hijo del mariscal de Navarra y de Castilla don Íñigo Ortiz de Estúñiga, y sobrino de Pedro de Estúñiga, conde de Ledesma y luego también de Plasencia. De familia navarra, por padre y por madre, esta última, doña Juana de Navarra, era hija natural del rey de aquellas tierras, Carlos III el Noble: nieto por tanto de rey, el cual debió de pagar, por lo que sabemos, la educación de sus nietos ${ }^{13}$.

La familia paterna desde el siglo anterior había apoyado a la corona castellana, trasladándose finalmente a Castilla. Tuvo otros cuatro hermanos. Producto de una política muy cambiante, apoyando en ocasiones a los navarros y aragoneses, y otras veces a Castilla, sin embargo tuvo don Íñigo casi siempre el favor de

Rey, sino también trovador; y tiene algunas poesías en el mencionado Cancionero" $(1779,205)$.

13 El mejor estudio sobre el autor sigue siendo el de Benito Ruano, E., (1968, 17-109). Recuperado de:

http://xn--revistadefilologiaespaola-uoc.revistas.csic.es/index.php/rfe/article/ viewFile/822/951 [Consultado el 25/10/2018]. 
Juan II. Este le recompensará pese a que, en dichas alternativas, también defendió los intereses de navarros y aragoneses.

Lope de Estúniga fue desde muy joven un ardoroso guerrero. Participó en el más famoso paso honroso medieval, el de Suero de Quiñones, su primo, en el puente leonés sobre el Órbigo, demostrando su valor con las armas ${ }^{14}$. Y, luego, hasta en quince pasos, contra "Roberto de Balse (Basilea) y diecinueve camaradas germanos" en Segovia, en agosto de 1435. Casi siempre salió victorioso $^{15}$.

Perfecto ejemplo de hombre de las armas y de las letras, como tantos de su tiempo, fue un reconocido poeta del que conservamos más de treinta composiciones ${ }^{16}$. Gracias a una de ellas, por abrir un famoso cancionero, recibió su nombre, el Cancionero de Estúñiga ${ }^{17}$. Su poesía, fundamentalmente amorosa, sigue los convencionalismos del amor cortés, que encontramos en tantos otros creadores de su tiempo (los Manrique, Juan Álvarez Gato, Antón de Montoro, Hernán Mexía, etc.), aunque - en contradicción con lo expresado en sus versos- sabemos que fue condenado a reclusión en su propio domicilio durante un año por maltratar a su esposa y derribar la puerta del convento toledano de Santo Domingo el Real, cuando acudió a recupe-

14 Sobre este famosísimo paso honroso se ha escrito mucho, casi siempre basándose en el testimonio de Pero Rodríguez de Lena, notario y escribano real, cuyo texto manuscrito sirvió de base para muchas versiones, entre otras la Crónica de don Álvaro de Luna. No se publicaría el texto de Rodríguez de Lena, Libro del paso honroso defendido por el excelente Suero de Quiñones hasta 1588 en Salamanca, Imprenta de Cornelio Bonardo.

15 Benito Ruano, E. $(1998,230)$.

16 Algunas de sus composiciones están recogidas por Foulché-Delbosc, R. (1912-1915). Recuperado de: http://archive.org. [Consultado el 25/10/2018]. Y, también, el más completo de Brian Dutton (1990-1991), El cancionero del siglo XV (13601520), Salamanca: Biblioteca Española del siglo XV, Vol. VII.

17 Un buen estudio sobre este cancionero, es el de Salvador Miguel, N. (1977). Sobre este cancionero y la poesía de Lope contenida, véase Alvar, M. (ed.) (1981) También Salvador Miguel, N. (ed.) (1987). 
rarla por la fuerza al esconderse de él en dicho lugar. Hombre de genio desabrido, conocemos diversas disputas que mantuvo con el alcalde mayor de Toledo, Pero López de Ayala.

Lope de Estúniga es autor de una composición que está formal y estructuralmente emparentada de forma directa con las Coplas de la panadera. Me refiero a su Decir de Lope de Estúñiga sobre la cerca de Atienza escrita en el año $1446^{18}$, uno después de la primera batalla de Olmedo (1445). Dicha plaza había sido, y continuaba siendo, contraria a Juan II y a su valido Álvaro de Luna, fiel a los infantes de Aragón y al rey de Navarra. Juan de Rebolledo la atendía en su nombre y defendió con valor frente al sitio que dispusieron las tropas de Juan $\mathrm{II}^{19}$. Lope de Estúñiga, cercano a Álvaro de Luna por interés económico, era, sin embargo, siguiendo la tradición familiar, filonavarro. Su familia anduvo en todo momento en serias dudas, especialmente a partir del momento en que su padre, Íñigo Ortiz, sufriera encarcelamiento durante dos meses por orden de los infantes de Aragón. Ello le decantó en la batalla de Olmedo por el bando de Juan II. Pero, a lo que parece, su hijo Lope siguió estando, pese a todo, próximo al otro bando. En todo caso, las alternativas se fueron sucediendo, como habitual era en la época. En su poema - Decir de Lope de Estúniga sobre la cerca de Atienza-, pese a ser un declarado partidario de don Álvaro de Luna, por intereses económicos, elogia la heroica defensa realizada por los cercados frente a las tropas del condestable de Castilla y de Juan II.

Pero el interés de dicha obra no está solo en lo que en ella se cuenta, sino especialmente en su composición formal. Se trata de un decir en octosílabos, agrupándose las redondillas de dos en dos -cuatro versos más otros cuatro-, excepto al principio y en el final, donde hay una sola redondilla, y un estribillo, con-

18 Cito esta obra dentro del estudio que la reproduce, Benito Ruano (1968, 9496). En adelante: DLE

19 Sobre la historia de la localidad de Atienza y aquellos hechos que cuenta Lope de Estúñiga, véase Serrano, L. $(2004,170)$. 
formando una novena o eneagésima. Dicho estribillo es: “ $\mathrm{i} A \mathrm{y}$, Margarida!". La apertura de la composición es la siguiente:

Saber deves, Margarida, lo que razonan agora de la gente defensora que non pudo ser vencida. ¡Ay, Margarida! (DEL: vv. 1-5)

Obsérvese la semejanza del texto anterior, comienzo del poema, con el de las Coplas de la panadera (también redondilla y estribillo) en la edición del texto que reproduce Julio Rodríguez Puértolas (1981), tomado a su vez del de Miguel Artigas y este del manuscrito de la Biblioteca Menéndez Pelayo ${ }^{20}$ :

Panadera, soldadera,

que vendes pan de barato, cuéntanos algún rebato que te aconteçió en la Vera.

¡Di, Panadera! (Rodríguez Puértolas, 1981: 131, vv. 1-5)

Hay una clara relación de semejanza en los dos textos por la presencia de dos mujeres (Margarida, panadera) y por el tono de los versos transcritos. En el segundo caso, la panadera es reclamada para que cuente algún rebato o noticia; mientras que, en el primero, a Margarida se le pide que escuche. Por otra parte, la panadera soldadera forma parte de una colección de personajes de tradición popular y folklórica, y no está encarnada en una persona con nombre individualizado, sino simplemente denominada por su oficio. Mientras que Margarida es nombre de mujer y no de oficio, de cierto nivel social por tener algunos referentes de

20 Rodríguez Puértolas, J. (1981, 127), señala que el texto que reproduce se basa en el señalado de "Miguel Artigas, "Nueva redacción de las Coplas de Ay Panadera según un manuscrito de la Biblioteca de Menéndez y Pelayo", en Estudios in Memoriam de A. Bonilla y San Martín, I (Madrid, 1927), 75-89". 
la alta nobleza, entre otros una tía suya, hermana de su madre Juana, e hija natural, como aquella, de su abuelo, el rey Carlos III de Navarra ${ }^{21}$.

Dicha oposición entre Margarida / panadera se traslada a la diferente concepción poética de ambos textos. El poema del cerco de Atienza tiene autor conocido - que aparece en el título, Lope de Estúñiga-, está escrito en lenguaje culto; mientras que el de las Coplas, anónimo, se encuentra dentro del catálogo de las obras destinadas a distribuirse clandestinamente. Con este fin, su autor emplea un lenguaje en ocasiones soez. Sin embargo, la estructura poética es exactamente igual en ambos casos.

En los dos, además de aparecer una mujer como referente al inicio de la composición - en el estribillo-, la estructura es la misma: exclamación con el apóstrofe "jay! o "di", seguido de pausa y el nombre de la mujer u oficio de la misma ("Di, panadera"/ “Ay Margarida!”).

Como se puede observar en el siguiente ejemplo de una y de otra, la rima es siempre abbaabbaa:

En el decir de Estúñiga:

$\begin{array}{ll}\text { O gente que sin medida } & \text { a } \\ \text { sobrastes los doze pares, } & \text { b } \\ \text { la qua! la planeta Mares } & \text { b } \\ \text { para si tovo escogida; } & \text { a } \\ \text { de virtudes noblescida, } & \text { a } \\ \text { encargada de vergüenza, } & \text { b } \\ \text { por do pudo bien Atienza } & \text { b } \\ \text { ser por armas defendida. } & \text { a } \\ \text { ¡Ay, Margarida! } & \text { a (DLE: vv. 6-14) }\end{array}$

21 Narbona Cárceles, M. da noticia de diversas mujeres de nombre Margarita de aquella corte, entre otras la referida infanta; también Margarita de Beaumont, hija de Carlos de Beaumont. Dicha investigadora registra otra Margarita hija de Lancelot, hijo natural este último de Carlos III $(2006,142)$. 
Y en las Coplas de la panadera ${ }^{22}$ :

$\begin{array}{ll}\text { Un miércoles que partiera } & \mathrm{a} \\ \text { el príncipe don Enrique } & \mathrm{b} \\ \text { a buscar algún buen pique } & \mathrm{b} \\ \text { para su espada ropera; } & \mathrm{a} \\ \text { salió sin otra espera } & \mathrm{a} \\ \text { de Olmedo tan gran compaña, } & \mathrm{b} \\ \text { que con muy hermosa maña } & \mathrm{b} \\ \text { fermoso, se retruxera. } & \mathrm{a} \text { (LP: vv.1-8) } \\ \text { [Di, panadera] } & \mathrm{a}\end{array}$

Ambos subgéneros poéticos (copla en un caso; decir en el otro) pertenecen, junto con las serranillas, las canciones y otras de su clase a la literatura de tradición oral ${ }^{23}$. Ello se corrobora por la presencia del estribillo y de la métrica octosilábica, característica de la lírica tradicional castellana.

Sin embargo, está muy claro que ambas se diferencian en el uso lingüístico. El Decir sobre el cerco de Atienza está escrito siguiendo una estructura de raíz cancioneril culta. Las referencias a Scévola, a Antioquía, a Troya o al héroe Héctor lo corroboran. Por el contrario, las Coplas están emparentadas con las cantigas de escarnio o de maldecir y con la literatura satírica destinada a circuitos de clandestinidad.

El espíritu de ambas composiciones es totalmente contrario. En el caso de las Coplas, hay un deliberado deseo de zaherir, mientras que el decir de Estúñiga es un elogio del valor de los sitiados en Atienza por las tropas de Juan II y Álvaro de Luna. Ello explica que en el primer caso abunden los adjetivos peyorativos,

22 La edición de Elia, P. (2002), basada en el "Pequeño Cancionero) (Ms 3788 $B N M)$, no trae el estribillo "Di, Panadera" de la edic. de Rodríguez Puértolas (1981) o el conocido de "¡Ay, panadera!" que da título a la composición. Con dicho estribillo, tendríamos la consabida estrofa de nueve versos y la misma rima señalada abbaabbaa.

23 Quizás el mejor estudio sobre los decires se encuentra en Lapesa, E. (1954). 
y los meliorativos en el otro. Aunque, en realidad, tanto en una como en otra se satiriza - de forma directa en las coplas- la política castellana, navarra y aragonesa de continua confrontación.

Ambas coinciden en la concepción narrativa del texto. Los dos relatos se cuentan con mucha efusividad, con imprecaciones, exclamaciones, llamadas al lector o ruegos, de forma muy visual. En diversas ocasiones, en las Coplas, como ya he señalado, aparece el verbo "vi" para dar mayor realidad y solvencia - como habitual era-, así como credibilidad, a lo contado. También en el decir sobre el cerco aparece presente el verbo ver, aunque en segunda persona:

Como vistes la venida del senior Rev de Castilla, por las faldas de la villa vuestra gente fue salida; la suya non resçibida con muy grandes alegrías, de malas noches e días fue por vosotros servida. ¡Ay, Margarida! (DLE: vv. 15-23)

Los dos textos se refieren de forma directa al lector/oyente porque ambos debieron de conocerse mucho más por el oído que por la lectura. Las Coplas lo dejan claro en los últimos versos:

Este fecho proçediera, según oyen mis orejas, por las notables yglejas quel el dicho rey destruyera, (LP: vv. 337-340)

En el decir de Estúñiga, todo ello es más evidente. Se alude a la necesidad de que quede memoria de los hechos que se cuentan a mayor gloria de sus héroes. En este ejemplo puede apreciarse, en la referencia que hace su autor a la memoria, tal y como insis- 
ten también Mena o Jorge Manrique en sus poemas contemporáneos:

¡O quánto será cundida vuestra defensa valiente en dotrina de la gente por memoria esclarescida. De vosotros resistida la fuerça del rey d' España, con poco vuestra fazaña non podiera ser creída. ¡Ay, Margarida! (DLE: vv. 51-59)

También en los siguientes:

Por çierto, bien comedida vuestra viril defensión, deve, con mucha razón, por el mundo ser sabida. $¡ \mathrm{O}$, quanto será leida por quien de vos subcedíere la corónica que fuere de vosotros escrevidal ¡Ay, Margarida! (DLE: vv-78-86)

El decir de Estúñiga trae una despedida, como habitual solía ser en los decires, siguiendo una fórmula tradicional - uso del verbo taño como si fuera un juglar que ha cantado su canción de los hechos heroicos de los sitiados en Atienza- que, sin embargo, no aparece en el caso de las Coplas ${ }^{24}$. Se despide en el primer texto de esta forma: 
Pues deve ser fenesçida

mi fabla, que mucho tarda,

concluyo, que sin reguarda

taño luego de acogida.

¡Ay, Margarida! (DLE: vv. 177-181)

En curioso que, pese a ser el decir de Lope de Estúñiga una pieza del cancionero, esté llena de recursos y fórmulas ajuglaradas y de la rica tradición oral: presencia del verbo ver, alusión a los que escuchan la composición, despedida como hacían los juglares aludiendo a su poema en su forma musicada, etc.

En las dos composiciones se citan con nombres propios a diversos personajes, héroes o villanos del relato. En el caso del decir aparecen nombrados Juan II, el condestable, Pedro Barahona o Rebolledo.

Hay, además, repetición de lexías en ambos textos. En las dos aparece la voz "mina" o "minera" 25 . En el decir de Estúñiga:

Por ver la [cerca] sumida con minas e con pertrechos, non çesaron vuestros fechos a la defensa devida. [...] (DLE: 33-36)

Y en las Coplas de la panadera:

Tú, Señor, que eres minera de toda virtud divina, sácale tu melezina de la tu santa triaquera; [...] (LP: vv. 345-348)

En los dos poemas hay alusiones a Dios o al Señor para que pare la guerra y traiga cordura a los nobles.

25 Sobre esta interesante voz, véase el trabajo de Puche Lorenzo, M.A. (2012, 791-800). 
En definitiva, ambos textos tienen parecidas estructuras formales y una misma unidad de sentido: la condena de la guerra. $Y$ los dos utilizan fórmulas poéticas muy parecidas. Ambos participan de los recursos de la literatura oral de que he dado cuenta. Y los dos tienen muchas más coincidencias que diferencias a todos los niveles.

Los dos se escribieron en fecha muy cercanas - 1445 las Coplas de la Panadera; 1446 el decir sobre el cerco de Atienza-. En realidad, esta última parece una continuación de aquella, su segunda parte. Si las Coplas concluyen con la acusación contra el rey de Navarra por haber provocado el conflicto, en el decir se acaba la confrontación. No hay lugar a la derrota ignominiosa. Atienza será ejemplo de una victoria de las tropas castellanas; pero la defensa realizada por los navarros será ejemplo -en opinión de Lope de Estúñiga- para generaciones futuras por su pundonor y valentía. Excelente manera de mostrar, tal y como aparece en las Coplas de la panadera, el conflicto interno que debió suponer para el escritor, Lope de Estúñiga, la guerra entre castellanos y navarros, como señalo a continuación ${ }^{26}$.

\section{Razones textuales que justifican la atribución de la obra a Lope de Estúñiga}

A lo largo de las Coplas de la panadera hay varias alusiones a La Vera, región extremeña, concretamente tres. De hecho, la panadera soldadera se localiza en La Vera ("cuéntanos algún rebato que te aconteció en la Vera") ${ }^{27}$. Aunque en ello se pueda entender

26 Para Fernando Castillo Cáceres (2009, 181-218), las Coplas de la panadera son una anticrónica de la batalla de Olmedo, por no respetar nada de la verdad de lo ocurrido aquel día de mayo de 1445. Por su parte, J. Paz opone la "versión oficial" a la narración poetizada de las Coplas. Véase Paz (1925). Filios D.K., en la línea anterior, señala que la batalla de Olmedo es completamente reescrita en la obra: $(2003,345-$ 363). Recuperado de: tp://www.jstor.org/stable/3247246. [Consultado el 25/10/2018].

27 Según Elia, P. en su edición de la obra, la "vera" que aparece en la composición pudiera referirse en realidad a la "ribera". Según esta investigadora: "En la Versión oficial de la batalla se lee "por lo que el dicho príncipe, mi hijo, se ovo de retraer fasta la ribera que estaba delante de mi real" $(2002,46)$. Sin embargo, en la 
que se trata de una alusión a la lírica tradicional - pues aquella región siempre se ha caracterizado por su carácter rural y folklórico, como tierra rica en tradiciones populares-, puede verse, sin embargo, una referencia de mayor alcance. No debe ser casual la presencia de aquella comarca en la obra, cuya capital era, y sigue siendo, Plasencia, convertida en condado cuya titularidad se otorgó al hermano de Íñigo Ortiz de Estúñiga, don Pedro de Zúñiga y Leiva, tío carnal de Lope de Estúñiga, tres años antes de la batalla de Olmedo .

En 1442, el rey Juan II nombró a Pedro de Zúñiga primer conde de Plasencia-título creado entonces- a cambio del señorío de Trujillo, entregado entonces a su hijo Álvaro, quien había perdido a su vez el ducado de Arévalo, convertido en realengo ${ }^{28}$.

¿Se trata de un guiño que del autor de las Coplas de la panadera? Probablemente. De hecho, la presencia de la familia Estúñiga en las Coplas la encontramos inmediatamente después de los versos que hablan de la actuación del rey en los actos bélicos, por delante del resto de nobles y antes que todas las dignidades religiosas. Esta presencia tan destacada de la familia Estúñiga en la obra, abriéndola prácticamente, es digna de ser anotada y muestra de que su autor la sitúa por encima del resto de nobles y dignidades, y solo por detrás del rey.

El orden de aparición tan estelar en la obra es muy revelador. Quizás alguien se apercibió de tal circunstancia y creyó que se debía buscar dentro de la familia Estúñiga a su autor. De hecho, incluso en las soeces Coplas del provincial se guarda un orden riguroso en la presentación de los diferentes personajes, siguiendo el estatus estamental y posición en la pirámide social ${ }^{29}$.

edic. de Rodríguez Puértolas, J. se señala que es una "comarca con Plasencia como cabecera" $(1981,131)$.

28 Véase Fernández, A. $(1627,94)$.

29 En las Coplas del provincial aparecen, tras el rey Enrique IV, el marqués de Cañete y el duque de Alburquerque. Más tarde, dentro de un segundo nivel, (Beltrán de la Cueva, conde de Benavente, conde de Ribadeo, de Rojas, etc. Y, luego, otros 
Además, los versos que se refieren a esta familia - los Estúñiga- son muy explícitos acerca de la intención del autor:

La de Çúñiga, que era

escuadra bien conviniente,

la meytad de la su gente

sabe Dios lo que quisiera;

mas como gente grangera,

de su señor natural

con ardimiento leal

acompañó su vandera. (LP: vv. 17-24)

El creador de los anteriores versos conoce bien la discusión que debió suscitarse en el seno de la familia Estúñiga cuando se recibieron las llamadas del rey y del condestable para acudir a la lucha. Pese a su filiación pronavarra, sin embargo, la citada cárcel sufrida por Íñigo Ortiz durante dos largos meses inclinó la balanza del lado castellano. Sabemos que Lope de Estúñiga, su hijo, era claramente filonavarro, pero mantenía una buena e interesada relación con el condestable, quien le facilitó importantes ingresos por su condición de trece de la orden de Santiago. De manera que lo que los anteriores versos están explicando es el conflicto que había dentro de la familia Estúñiga. Aunque dicha circunstancia debió darse en otras familias, solo la de esta aparece mencionada en las Coplas de la panadera.

Por otra parte, su autor califica de "bien conveniente" a la escuadra de los Estúñiga, de forma marcadamente positiva. Subraya además la obediencia a su "señor natural", su lealtad -“ardimiento leal"- y la defensa del estandarte familiar. En ningún otro caso de los presentes en las Coplas de la panadera se habla de familia, sino tan solo de individuos. El único ejemplo en toda la obra, encabezando el texto y solo tras el rey, es el de los Estúñiga, que aparecen como núcleo familiar. ¿Por qué razón? Muy proba-

señores o clérigos con menor rango estamental: prior de León, Alonso de Aguilar, Cristóbal Platero, Álvaro Pérez de Castro, etc. 
blemente porque su autor - Lope de Estúñiga- no participó en la acción bélica, pero se cree representado por los otros miembros de su familia que sí participaron. De alguna manera, explicando las divisiones en los Estúñiga, se excusa por no formar parte de la acción guerrera. Cierto es que, en tal caso, miente cuando repite "vi" en varias ocasiones. Quienes sí vieron fueron su padre, su tío Pedro y el hijo mayor de la familia, Diego de Estúñiga. Pero no creo que participara Lope. Su mejor biógrafo, Benito Ruano, solo documenta una acción bélica a lo largo de toda su vida, la toma de Huelma con el capitán Fernán Álvarez en 1434 (1968, 39). Ello no significa que no pudiera ser informado por fuentes solventes: bastaba con preguntar a los suyos para tener razonada y detallada información sobre lo acecido en Olmedo aquel día 19 de mayo de 1445 .

Por otra parte, parece lógico que las Coplas se refieran a los Estúñiga como familia y no se nombre a ningún individuo en particular. Era la mejor manera de que Lope pudiera esconderse dentro del grupo. Ello es por tanto otro argumento para que busquemos dentro de ella a quien la escribió.

El autor de las Coplas de la panadera habla del comportamiento de dos miembros de la familia Quiñones, emparentados con los Estúñiga. Uno es Pedro de Quiñones, hermano de Suero de Quiñones, el famoso protagonista, junto con Lope, su primo, del más famoso paso honroso de toda la Edad Media. De él se dice en las Coplas de la panadera lo siguiente:

Assaz honroso acudiera

a sus valientes varones

Mossén Pedro de Quiñones

quando las piernas batiera;

tan adentro se metiera

quél oviera de aver fin,

mas allí con un faquín

mucho bien se sacudiera. (LP: vv. 153-160) 
Obsérvese cómo en el texto transcrito aparece el adjetivo "honroso" en el primer verso, recordando el autor - Lope de Estúñiga- que se trata del hermano de su primo Suero de Quiñones, con quien compartió aquella gloriosa aventura leonesa junto al río Órbigo. El tratamiento de sus tropas es muy positivo ("valientes varones") aunque no queda muy claro el sentido de los siguientes versos. ¿Se ríe de sus excesos guerreros o, por el contrario, cuando alude al faquín ('ganapán') se refiere a que solo combatió con pobres campesinos?

Mucho más clara es la mención al otro miembro de la familia, Fernando de Quiñones, que luchó con gran valor y que, de resultas de las heridas de la lucha, fallecería tiempo más tarde:

Fernando, que prometiera, de Quiñones, por su amor, de ser muerto o bençedor, cae muerto por la mollera; la Virgen, procuradera ques de todo hombre contrito, ruegue a su hijo bendito que le dé gloria llenera. (LP: vv. 329-336)

Hay también una clara alusión autobiográfica cuando el autor de Las coplas de la panadera menciona al "conde chiquito" Juan Niño-, conde de Huelma. Recordemos que en 1435 Lope de Estúñiga participó en la lucha por recuperar la localidad de Huelma, en la frontera de Jaén, contra los moros, la única batalla que reconoce como real - al margen de justas y pasos honrosos- su biógrafo Benito Ruano. Dice así en las Coplas:

Por persona consejera, don Joan, el conde chiquito, cabo el rey hincó su hito y tendió su harpillera, y dizen que le dixera: 
Señor, si passáys los trigos, sacaréys los enemigos

todos de la raposera". (LP: vv. 281-288)

Quizás Lope de Estúñiga no puede evitar traer a su recuerdo aquel momento de pelea contra los moros y, por tal razón, alude al conde de aquella localidad en cuya liberación él colaboró.

Sabemos, además, que el abuelo de Lope de Estúñiga, Diego López de Estúñiga, es primo de Íñigo López de Mendoza, lo cual explica los últimos versos tan elogiosos que dirige a su persona ("que vivas llamas de fuego/ pareció que les pusiera"). He localizado un documento en el Archivo Histórico de la Nobleza", de fecha 10 de abril de 1440, una "Carta de pago por Diego López de Estúñiga, justicia mayor, a favor de Íñigo López de Mendoza, su primo, en el que le da por libre de los florines del cuño de Aragón que le estaba obligado a pagar por los frutos de Castilnuevo como hijo y heredero de Pedro González de Mendoza"30.

Por otra parte, tanto Juan II como el condestable, Álvaro de Luna, no salen mal parados en las Coplas. El autor toma un tono neutro, muy tibio. La parte dedicada a Juan II, al comienzo de la obra, tan solo se refiere a la orden que dio de atacar cuando vio a su hijo Enrique en peligro. Y, en cuanto al condestable, los adjetivos que emplea son aduladores, pero no en exceso:

Obra muy clara y plaçera

se mostró ser, e notable,

la que hizo el condestable

con los que se combatiera;

mas quebraran la vasera

muy aýna sin dudança

si la su buena ordenança

algún poco se durmiera. (LP: vv. 209-216) 
Muy importante es la penúltima estrofa de Las coplas de la panadera, donde alude a lo siguiente:

Este fecho proçediera, según oyen mis orejas, por las notables yglejas que el dicho rey destruyera; el qual cierto meresçiera, por hazer tan gran pecado, que con su honra y estado al abismo se sumiera. (LP: vv. 337-344)

Ciriaco Morón Arroyo señaló que "la referencia final a la destrucción de iglesias por el rey Juan de Navarra permite sospechar que el autor fuera un clérigo"31. En realidad, la acusación está dirigida contra el rey de Navarra por haber invadido el valle del Henares (Torija, Atienza y Alcalá) en su camino a Olmedo en febrero de 1445. De hecho, todavía en el verano de 1446, el rey castellano y Álvaro de Luna seguirán intentando recuperar aquellas plazas ocupadas por los navarros, más de un año después de la batalla de Olmedo.

En ese contexto histórico hemos de situar el decir sobre la conquista de Atienza compuesto por Lope de Estúñiga: en verdad constituye la segunda parte poética, e histórica, de la batalla de Olmedo y de las Coplas de la panadera.

Al margen de ello, es evidente que la alusión al rey de Navarra está hecha en un contexto de amor/odio por todo lo que significa. Ya hemos visto cómo el autor de las Coplas de la panadera nos muestra las enormes dudas sobre a quién dar su apoyo. No olvidemos que Lope de Estúñiga es nieto de rey, del navarro Carlos III el Noble. Su cariño por aquella tierra es muy evidente. Pero su otro abuelo, Diego de Estúñiga, fue muy poderoso bajo la corona de Castilla, como justicia mayor del reino. Y Lope de Estúñiga 
se encontraba, por tanto, en un difícil compromiso cuando en febrero de 1445 Juan I de Navarra invadió Castilla a causa de la confiscación por Juan II de Castilla de las rentas que obtenía de Medina del Campo.

Lope no olvida que en 1430 el rey Juan I de Navarra le desposeyó de sus tierras de Navarra, cuando acudió en 1429, junto con su hermano Diego, en ayuda de Castilla, en la guerra entre los dos reinos. El rey navarro les arrebató a él y a sus hermanos la villa de Mendavia y el solar familiar de Zúñiga, que entregó al alférez Carlos de Beaumont, consejero del príncipe de Viana, D. Carlos, hijo este último de Blanca de Navarra. Las razones esgrimidas fueron las siguientes:

hobiendo esgoar á la naturaleza é crianza de su regno, et á la jura de la fealdad que eillos le eran tenidos, et olvidados las gracias, honores et bien fechos que habian rescebido del rey su padre, en el tiempo de la guerra que el rey de Castilla fezo á este regno, dejados et desamparados las fortalezas qui les habian acomendado, ocultament et sin sabiduría de la Seinoría, se absentaron del dicto logar (Mendavia), et pasaron al regno et partida de Castilla ${ }^{32}$.

En contrapartida, sin embargo, Juan II de Castilla quiso agradecerles su apoyo y resarcirles por la pérdida entregándoles la localidad de Cerezo en Burgos.

Las Coplas de la panadera nos muestran lo que en realidad estaba ocurriendo en el seno de la familia Estúniga: una curiosa relación de amor, pero también de odio, con ambos reinos y con ambos reyes de Castilla y de Navarra.

Sin duda, ninguna otra familia noble como los Estúñiga se encontró atrapada en tal disyuntiva. Por eso los versos que su autor, Lope, refiere a su familia en la obra. También, la forma de recriminar tan duramente al rey Juan I de Navarra. En su descargo, sin embargo, hemos de decir que este rey mandó en 1450 de- 
volver a los Estúñiga Mendavia y Zúñiga arrebatándoselas esta vez a los Beaumont.

Indudablemente, la impronta navarra de sus orígenes se hace presente en las Coplas de la panadera también al final del texto. Y se convierte, así, en otro elemento que demuestra la autoría de la obra por Lope de Estúñiga; el cual escribió, sin ninguna duda, las Coplas de la panadera, hastiado de que tanto unos como otros - castellanos y navarros- actuaran de forma tan irracional. Por ello las Coplas son un ajuste de cuentas y en ningún caso defienden interesadamente a ningún bando, como hace por ejemplo Pedro de Escavias, del lado del infante don Enrique de Aragón, o Juan de Mena acusando a Íñigo Ortiz de Estúñiga, padre de Lope, saliendo en defensa de los caballeros castellanos y del propio rey Juan II. De todos los posibles candidatos a autor de las Coplas de la panadera, el que mejor se encontraba en disposición de escribirla era él sin duda, por hallarse justo en el medio, atrapado en una terrible disyuntiva

\section{Conclusiones}

A lo largo de este estudio, he intentado descubrir la autoría de las Coplas de la panadera. Finalmente, he llegado a las siguientes conclusiones:

1‥ Después de analizar las atribuciones que se han hecho por los críticos y estudiosos, especialmente a Juan de Mena a Rodrigo Cota y a Antón de Montoro, desecho dichas posibilidades, tanto por razones estrictamente literarias como por su situación personal, especialmente de los dos últimos, en su condición de judeoconversos.

2a - - He analizado la posibilidad de que el autor fuera un poeta que participara en los hechos bélicos de la batalla de Olmedo (1445), tanto de un bando como del otro. Sin embargo, no creo en tal posibilidad. Descarto como autores por diversas razones tanto al Marqués de Santillana, como a cualquier miembro de la familia Manrique o a Pedro de Escavias, este último en el bando aragonés.

3a -- Doy credibilidad a la hipótesis de que el autor pertenece a la familia de los Estúniga y sigo la pista que tempranamente 
dio Mena en su contienda poética con Íñigo Ortiz de Estúñiga. Me decanto sin embargo por su hijo Lope. Entre otras razones, señalo que el primero apenas compuso poesía y, cuando lo hizo, fue en respuesta a provocaciones que he señalado.

4⿳亠丷. - Relaciono las Coplas de la panadera con el Decir de Lope de Estúñiga sobre la cerca de Atienza (1446), con la que coincide formalmente en la estructura métrica, rima, estribillo, empleo de voces y cronología (1445/1446). Ambas son muy críticas con la guerra y con las divisiones o luchas civiles de los reinos peninsulares.

5‥- Por otra parte, la referencia a "la Vera", cuya capital, Plasencia, se convirtió en condado solo tres años antes (1442) de la primera batalla de Olmedo es otro argumento a favor de la autoría que defiendo. El primer conde fue el tío de Lope de Estúñiga, Pedro de Estúñiga.

6 ${ }^{a}$ - Es muy significativa la aparición en la obra, exactamente tras Juan II de Castilla, de los Estúñiga, por delante de los prelados y del resto de nobles e infantes aragoneses así como del rey de Navarra. Su aparición estelar se añade al hecho de que no se señala a ningún miembro de la familia. Tal circunstancia no se da en ningún otro caso, pues siempre aparecen individuos. La razón es simple: el autor se esconde dentro del núcleo familiar. Aventuro a este respecto que Lope de Estúñiga no participó en la batalla de Olmedo, si hacemos caso a su principal biógrafo. Sin embargo, contaba con fuentes de información de primera mano: su padre, su tío Pedro y su hermano mayor, Diego, que sí sabemos que estuvieron. Por otra parte, Lope, como autor de las Coplas, nos presenta a una familia claramente dividida entre los que apoyaban a un bando y los que apoyaban al contrario. ¿Intento de justificar su ausencia?

7a.- Relaciono la presencia de diferentes individuos y la forma de presentación de los mismos con la biografía de Lope de Estúñiga. Así, encontramos a dos miembros de la familia Quiñones (Diego y Fernando), a su primo Suero de Quiñones, con quien participó en el más importante paso honroso de toda la 
Edad Media. La presencia de la voz "honroso" cuando se refiere a Diego de Quiñones es un guiño que hace Lope de Estúñiga y es un indicio más de su autoría.

8a -- Otro guiño autobiográfico lo hallamos en la presencia en las Coplas del "conde chiquito" - Juan Niño-, conde de Huelma, localidad en cuya liberación frente a los moros participó Lope de Estúñiga, en su única acción bélica conocida.

9a .- Respecto a Íñigo López de Mendoza, y tras aludir a que vestía a lo "extranjero", le dirige unos últimos versos elogiosos ("que vivas llamas de fuego/ pareció que les pusiera") quizás por tratarse del primo de su abuelo, Diego de Estúñiga.

$10^{\mathrm{a}}$.- Su juicio tibio tanto del condestable como de Juan II, así como del infante Enrique, se completa con una valoración positiva en la batalla del rey de Navarra, aunque en los últimos versos arremete contra él por la invasión de Castilla. He dado noticia de las razones de ello, en relación también con su biografía.

11‥- Concluyo que nadie como Lope estaba en mejor situación para escribir una obra como las Coplas de la panadera, como nieto del rey de Navarra y del justicia mayor de Castilla. La guerra civil entre Castilla y Navarra debió de parecerle algo indecente y de ahí su ataque contra unos y contra otros. El decir del cerco de Atienza sigue en la misma línea que las Coplas de la panadera, y parece en realidad la segunda parte de aquella, aunque con mejores galas: Margarida -nombre de su tía, hermana de su madre, ambas hijas de rey- en lugar de panadera; formas cultas en vez de vulgares; elogio del valor, frente a la sátira de la cobardía. Pero en realidad, ambas son la expresión de la sinrazón de la guerra, según opinión del autor de las dos obras: Lope de Estúñiga.

\section{Referencias bibliográficas}

Alvar, M. (ed.) (1981) Cancionero de Estúñiga, Zaragoza, Institución «Fernando el Católico».

Amador de los Ríos, J. (1863) Historia crítica de la literatura española, Madrid, Imprenta a cargo de José Fernández Cancela. 
Argote de Molina, G. (1866) Nobleza de Andalucia: que dedicó al Rey Don Felipe II don Gonzalo Argote de Molina, Jaén, Estab. tip. de Francisco López Vizcaino.

Benito Ruano, E., (1968) “Lope de Estúñiga. Vida y cancionero", Revista de Filología Española, vol. LI no 1/4, 17-109.

de la Historia. (1998) Gente del siglo XV, Madrid, Real Academia

Cantera Burgos, F. (2011) El poeta Rodrigo Cota y su familia Otros dos estudios sobre cancioneros, Miranda de Ebro, Fundación Cultural Profesor Cantera Burgos.

Castillo Cáceres, F. (2009) "Las coplas de la panadera, una anticrónica de la batalla de Olmedo", South Atlantic Review. Vol. 74, 1, pp. 181-218.

Costa, M. (1990) Antón de Montoro, Cleveland, Cleveland State University.

DutTon, B. (1990-1991) El cancionero del siglo XV (1360-1520), Salamanca, Biblioteca Española del siglo XV, Vol. VII.

Elia, P. (1983) Coplas hechas sobre la batalla de Olmedo que llaman las de la Panadera. Verona, Università degli Studi - Facoltà di Economia e Commercio.

(2002) El "Pequeño Cancionero". (Ms. 3788 BNM). Notas críticas y edición, A. Coruña, Toxosoutos.

Entrambasaguas, J. de (1974) Los Manrique: poetas del siglo $X V$, Zaragoza, Ebro.

Fernández, A. (1627) Historia y anales de la ciudad y obispado de Plasencia, Madrid, Juan González, p. 94.

Filios, D.K. (2003) "Rewriting history in the 'Coplas de la Panadera", Hispanic Review, 71, 345-363.

Foulché-Delbosc, R. (1912-1915) Cancionero castellano del siglo $X V$, Madrid, Bailly-Bailliére, 2 vols.

García-Bermejo Giner, M. (2015) “La comicidad híbrida de las [Coplas de la Panadera]", en Toro Ceballos, F. (ed.) Los reinos peninsulares en el siglo XV. De lo vivido a lo narrado. Encuentro de investigadores en homenaje a Michel García. Andújar Ayto.- Asoc. Cult. Enrique Toral y Pilar Soler, 87-100. 
García, M. (1997) Entre Santillana y Manrique: El poeta Pedro de Escavias en su siglo, Jaén, Instituto de Estudios Giennenses.

Guglielmi, N. (1970) “Los elementos satíricos de las Coplas de la Panadera", Filología, 14, 49-104.

Lapesa, E. (1954) Los decires narrativos del marqués de Santillana, Madrid, R.A.E.

Lida de Malkiel, Ma. R. (1950) Juan de Mena, poeta del prerrenacimiento español, México, Colegio de México.

Marcos Ávarez, F. B (1979) “Dos notas sobre poesía menor de Juan de Mena", en Estudios ofrecidos a Emilio Alarcos Llorach, vol. 4, 441-454.

Menéndez Pelayo, M. (1890) Antología de poetas líricos castellanos desde la formación del idioma hasta nuestros días, Madrid, Imprenta de la Viuda de Hernando.

Menéndez Pidal, R. (1957) Poesía juglaresca y juglares, Madrid, Instituto de Estudios Políticos.

Morales, M (1997) Hernán Mexía, escritor giennense del siglo $X V$, Jaén, Diputación Provincial.

Morón Arroyo, C. (1989) Antología de la lírica medieval, Madrid, Publicaciones del Colegio de España.

Narbona Cárceles, M. (2006) La corte de Carlos III el Noble, Pamplona, Ediciones Universidad de Navarra.

PAz, J. (1925) “Versión oficial de la batalla de Olmedo (1445)”, en (ed). Homenaje ofrecido a Menéndez Pidal: miscelánea de estudios lingüísticos, literarios e históricos, 3 vols. T. I., 839-842.

Pérez Priego, M.A. (2004) “Temas y formas de la poesía cancioneril: la lírica de Juan de Mena", en Estudios sobre la poesía del siglo XV, Madrid, UNED-Cuadernos de la UNED, 109-140.

Puche Lorenzo, M.A. (2012) “Ficción, mito y realidad de la voz mina en la Edad Media", en Martínez Pérez, A. y Baquero Escudero, A.L. (ed.), Estudios de Literatura Medieval. 25 años de la Asociación Hispánica de Literatura Medieval: 25 años de la AHLM, Murcia, Universidad de Murcia, 791-800. 
Rodríguez Puértolas, J. (ed.) (1981) Poesía crítica y satírica del siglo XV, Madrid, Castalia.

SÁNCHEZ, T.A. (1779) Colección de poesías castellanas anteriores al siglo XV, Madrid, Antonio de Sancha.

Salvador Miguel, N. (1977) La poesía cancioneril. El «Cancionero de Estúñiga», Madrid, Alhambra.

Serrano, L. (2004) Historia de la villa de Atienza, Guadalajara, Aache Ediciones.

Toral, E. (1993) Pedro de Escavias: Notas para un estudio de su obra y vida en Andújar, Jaén, Instituto de Estudios Giennenses.

Uhagón, Francisco R. DE (1900) “Un cancionero del siglo XV con varias poesías inéditas (conclusión)", Revista de Archivos, Bibliotecas y Museos, $\mathrm{n}^{-}$9, pp. 516-535.

Vànvaro, A., (1964) Premese ad un'edizione critica delle poesie minori di Juan de Mena, Napoli, Liguori.

VV.AA. (1977) Homenaje de Antón de Montoro en el V centenario de su muerte, Montoro, Imprenta San Pablo.

Yanguas y Miranda, J. (1840) Diccionario de antigüedades del reino de Navarra, Pamplona, Imprenta de José Imaz y Gadea, p. 542 del tomo III. 